\title{
Educação sobre drogas: uma proposta orientada pela redução de danos
}

\author{
Mariana Adadel \\ Simone Monteiro'
}

\section{Resumo}

Diante do fracasso das políticas centradas na condenação do uso de drogas, este trabalho visa contribuir para o desenvolvimento de uma proposta educativa informada pela contextualização dos aspectos socioculturais, econômicos e políticos desse fenômeno e pelo conceito de redução de danos (RD). Para tanto, por meio de entrevistas, investiga as visões sobre drogas e temas afıns de 40 escolares dos ensinos fundamental e médio, das redes pública e privada do Estado do Rio de Janeiro. Ademais, revisa o conteúdo de um jogo educativo sobre o uso indevido de drogas denominado Jogo da Onda, com base na análise documental do material. As entrevistas revelaram que a maioria dos estudantes tem uma concepção negativa das drogas ilícitas, minimiza os riscos do consumo das drogas lícitas e não considera as singularidades dos elementos envolvidos no consumo (sujeito, tipo de droga e contexto de uso). Tais achados, somados à revisão bibliográfica, orientaram a atualização do conteúdo do Jogo da Onda e a proposição de novas temáticas a serem incorporadas na nova edição do material. Em face das lacunas na formação dos educadores em relação ao tema das drogas, da escassez de recursos educativos participativos e do interesse dos estudantes em dialogar sobre o assunto, este estudo pretende fornecer subsídios para o desenvolvimento de ações educativas sobre drogas entre jovens, pais e educadores.

\section{Palavras-chave}

Educação - Drogas e juventude - Redução de danos - Jogos educativos.

I- Fundação Oswaldo Cruz, Rio de Janeiro, RJ, Brasil. 


\title{
Education about drugs: a proposal oriented by damage reduction
}

Mariana Adadel

Simone Monteiro'

\begin{abstract}
In view of the failure of policies centered on the condemnation of drug abuse, this work aims at contributing to the development of an educative proposal informed by the contextualization of socio-cultural, economic and political aspects of this phenomenon, and by the concept of damage reduction (DR). For that, making use of interviews, the work investigates the views about drugs and related issues expressed by 40 students from both public and private primary and secondary education schools in the State of Rio de Janeiro. Furthermore, it reviews the contents of an educative game about the inadequate use of drugs called Jogo da Onda (Wave Game) based on the documental analysis of the material. The interviews revealed that most students have a negative view of illegal drugs, minimize the risks of consuming them, and do not consider the singularities of the elements involved in the consumption (subject, type of drug, and context of use). These findings, added to the bibliographic review, guided the update of the content of the Jogo da Onda, and the proposition of new themes to be incorporated in a new edition of the material. In view of the gaps in the formation of educators regarding the theme of drugs, the lack of participative educative resources, and the interest of students in talking about this subject, this study attempts to give elements for the development of educative actions about drugs among youngsters, parents and educators.
\end{abstract}

\section{Keywords}

Education - Drugs and youth - Damage reduction - Educative games.

I- Fundação Oswaldo Cruz, Rio de Janeiro, RJ, Brazil.

Contacts: mariana_adade@hotmail.com; msimone@ioc.fiocruz.br 
As limitações e o insucesso das abordagens proibicionistas voltadas para o controle e a prevenção do uso indevido de drogas têm sido atestados por diversos estudos e pelo crescimento regular do uso de drogas entre jovens nas ultimas décadas, particularmente do álcool (BASTOS et al., 2008; GALDURÓZ et al., 2010). Tais evidências têm motivado a revisão de políticas públicas descontínuas e descontextualizadas, historicamente orientadas por perspectivas teórico-metodológicas de caráter repressivo e informativo, visando unicamente ao não consumo de drogas. Nesse enfoque, a droga é definida como um mal que precisa ser exterminado e as pessoas são consideradas indefesas e passivas diante das substâncias ilícitas, necessitando de proteção e orientação de autoridades médicas e jurídicas (BUCHER, 2007; CANOLETTI; SOARES, 2005). Em contraposição a essa visão, há novas formas de compreender e intervir no controle e na prevenção do uso indevido de drogas, como a abordagem de redução de danos (RD) (SOARES; JACOBI, 2000; CARLINI-COTRIM, 1992).

Segundo a defınição da OMS, a RD é uma estratégia de auxílio ao usuário na redução do consumo de drogas que pode contribuir para uma possível interrupção do seu uso (WHO, s.d.). Com base em revisão da literatura, Santos, Soares e Campos $(2010,2012)$ constataram que existem variações conceituais sobre a RD, decorrentes da apropriação da abordagem por diferentes campos disciplinares e contextos, sendo recomendada a definição do embasamento teórico e metodológico do termo nos trabalhos que partem dessa perspectiva. $\mathrm{Na}$ presente pesquisa, adota-se uma visão ampliada, global e crítica sobre a realidade social na compreensão do fenômeno das drogas. Assim, a concepção de RD utilizada centra-se em um conjunto de saberes e práticas acerca do uso de drogas fundamentados no conhecimento amplo da realidade histórica e sociocultural. Dentre eles, destaca-se a evidência de que a produção, o comércio e o consumo de drogas são práticas que sempre estiveram presentes na história da humanidade, ganhando signifıcados e funções de acordo com o momento social, político e econômico de cada sociedade. Considerando a inevitabilidade do uso de drogas, as ações de RD objetivam minimizar os prejuízos individuais e sociais associados a essa prática a partir do respeito às diversas singularidades e do resgate do direito individual de escolha e de acesso aos serviços de saúde (SANTOS; SOARES; CAMPOS, 2010).

No campo da educação sobre drogas, Acserald (2005) faz uma aproximação da abordagem da RD com a perspectiva de educação para autonomia defınida por Freire (2008), que afirma que o processo de aprendizagem deve ser permeado por um conhecimento crítico da realidade. Ou seja, aprender transcende o armazenamento de saberes, sendo resultado de uma constante reflexão sobre a realidade global. De acordo com essa perspectiva, o educador e o educando são sujeitos ativos do processo de construção de conhecimento, aprendendo mutuamente por meio de sucessivas aproximações e reflexões sobre determinado assunto. A aprendizagem é facilitada pelo educador por meio de técnicas reflexivas e participativas que visam ao estímulo do raciocínio crítico diante de temas específicos contemplados com base na inserção na realidade social. 0 processo de aprendizagem global, crítico e emancipatório torna-se possível a partir do reconhecimento do educando como um ser histórico, distante de uma perspectiva determinista e naturalizada não só do seu papel enquanto sujeito social, mas de todos os elementos que compõem seu cenário de vida. Educar é aprender a ser cidadão tanto de direitos quanto de deveres, é estar habilitado para transformar sua realidade levando em consideração não só os interesses individuais, mas também os interesses coletivos (FREIRE, 2008).

Com base na revisão da literatura internacional na área de educação sobre drogas, Paglia e Room (1998) constataram a carência de estudos sobre práticas de RD. Todavia, as experiências existentes foram avaliadas positivamente. Os autores salientaram que os 
benefícios das estratégias educativas não podem ser relacionados apenas à diminuição ou não do consumo de drogas. A proposta da RD centra-se em um trabalho processual de conscientização e emancipação do sujeito enquanto cidadão; daí a importância de ações contínuas e do envolvimento dos jovens no processo de criação e implementação das atividades educativas (FEFFERMANN; FIGUEIREDO, 2006; SOARES; JACOBI, 2000).

As evidências do fracasso das políticas de guerra às drogas, somadas às novas perspectivas sobre o tema, como a RD, têm potencializado a mobilização e a articulação de profissionais de diversas áreas do conhecimento e promovido a ampliação da discussão sobre as diretrizes legais e as ações de controle do uso indevido de drogas entre diferentes esferas da sociedade (ACSERALD, 2005; BUCHER; OLIVEIRA, 1994; SOARES, 1997). Para ilustrar, cabe citar a criação da Comissão Brasileira sobre Drogas e Democracia (CBDD), formada por atores de diferentes setores da sociedade que se propõem a pensar a política de drogas e intermediar a comunicação entre especialistas, o governo e a opinião pública. Outros exemplos são: o projeto Lei de drogas: é preciso mudar!, capitaneado por uma organização não governamental que visa transformar a atual legislação, e as manifestações populares que reivindicam o direito de cultivo e consumo da maconha, realizadas em vários estados do Brasil. 0 tabaco, por sua vez, tem sido alvo de campanhas da mídia que evidenciam os malefícios do consumo continuado e abusivo e de intervenções legislativas referentes à restrição à divulgação de propagandas nos veículos de comunicação e à proibição do consumo em espaços de sociabilidade (NOTO et al., 2003).

$\mathrm{Na}$ educação escolar está prevista a inclusão da temática das drogas nos currículos da educação infantil e dos ensinos fundamental e médio, uma vez que ela faz parte do cotidiano juvenil. Segundo os Parâmetros Curriculares Nacionais (PCN), tal tema deve ser abordado transversalmente aos conteúdos programáticos tradicionais, a partir de estratégias definidas pelas escolas (ARAÚJO, 2001; FEFFERMANN; FIGUEIREDO, 2006). No âmbito da legislação brasileira, embora a Lei $n^{\circ}$ 9.394/96 não apresente um item sobre drogas, a Lei $n^{\circ}$ 11.343/2006 regulamenta a formação continuada de professores na área de prevenção ao uso indevido de drogas e recomenda a implantação de projetos pedagógicos no ensino público $\mathrm{e}$ privado (BIZZOTTO; RODRIGUES, 2007). Assim, reafirma-se legalmente a responsabilidade da escola e do professor na formação social e intelectual dos sujeitos, incluindo uma formação educacional a respeito das drogas.

Embora o contexto formal de ensino seja reconhecido como um local privilegiado para as ações educativas sobre drogas, os estudos sinalizam um descompasso entre as diretrizes acadêmicas e o despreparo (teórico e afetivo) do educador para assumir essa tarefa, o que se expressa nas omissões e/ou negações para abordar o assunto. Ou seja, os educadores recebem a demanda para incluir o tema nas atividades curriculares, mas não são fornecidos subsídios para tal implementação. A literatura constata que a resistência dos educadores em desenvolver tal conteúdo no contexto escolar está vinculada à falta de formação apropriada e às ideias preconcebidas acerca das relações entre droga, violência e criminalidade (CARLINIMARLATT, 2001; MARTINI; FUREGATO, 2008; MOREIRA; SILVEIRA; ANDREOLI, 2006; SOARES; JACOBI, 2000).

No que se refere às iniciativas na área de ensino de ciências associadas à temática, as publicações encontradas foram predominantemente resumos estendidos e relatos de experiências em sala de aula apresentados em eventos da área. Parte dos trabalhos privilegiou a discussão sobre a formação do professor, sugerindo que esta seja orientada para a integração curricular em prol da superação das disciplinas ministradas de forma compartimentada (BOFF et al., 2009). Nesse sentido, Cavalcante et al. (2005) investigaram as representações sociais sobre drogas de um grupo de professores da rede pública de um município na Bahia. Entre 
os entrevistados prevaleceram representações negativas acerca das substâncias e dos usuários. Os autores reforçam a importância da formação inicial e continuada sobre o tema, tendo por base o manejo das representações dos educadores e uma visão ampliada do fenômeno das drogas.

Vale ressaltar que tem havido iniciativas nas áreas da saúde, da educação e da justiça visando à capacitação de professores para o manejo do tema, como o Curso de Prevenção do Uso de Drogas para Educadores de Escolas Públicas, organizado pela Secretaria Nacional de Políticas sobre Drogas (Senad), em parceria com a Secretaria de Educação Básica do Ministério da Educação (MEC). 0 curso faz parte do Plano Integrado de Enfrentamento ao Crack e outras Drogas desde 2004 e a próxima edição será ministrada em oito meses, a partir de agosto de 2012 . $^{1}$

Em suma, existem desafios na prevenção do uso indevido de drogas que implicam o envolvimento de vários setores e atores sociais dos campos da saúde, da educação e da justiça. Integra esse esforço o desenvolvimento de abordagens educativas capazes de contemplar aspectos caros da interação, como o contexto sociocultural e econômico e a dimensão simbólica das populações que são alvo das ações (ACSERALD, 2005; SOARES, 1997).

Com o propósito de contribuir para o incremento de práticas educativas sobre drogas afınadas com a RD, o presente trabalho objetiva investigar as visões de escolares das redes pública e privada do Estado do Rio de Janeiro sobre esse fenômeno, bem como revisar o conteúdo de um jogo educativo sobre o uso indevido de drogas, denominado Jogo da Onda (REBELLO; MONTEIR0, 1998), com base na análise documental do material. Desenvolvido por pesquisadoras do Laboratório de Educação em Ambiente e Saúde (LEAS) do Instituto Oswaldo Cruz (IOC), esse jogo foi adotado por programas de educação em saúde da Secretaria Estadual de Saúde do Rio de Janeiro e da Secretaria

1- Informações disponíveis em: <www.brasil.gov.br/enfrentandoocrack plano-integrado>. Acesso em: 31 mar. 2013.
Municipal de Educação de São Paulo, dentre outras ações nos âmbitos público, privado e da sociedade civil (MONTEIRO; REBELLO, 2005). Desde 2008 o jogo está esgotado e existe uma demanda contínua pelo material, atestada por contatos dirigidos ao LEAS/IOC por parte de instituições e profissionais da área da educação e da saúde, das redes pública e privada de diferentes regiões do Brasil (ver quadro 1).

A opção pela atualização do conteúdo do Jogo da Onda resultou da revisão de estudos sobre educação e drogas no contexto nacional. A partir dos artigos sobre o desenvolvimento e a avaliação do jogo, foi possível conhecer o referencial teórico utilizado pelas autoras o qual é relacionado à RD e à educação para autonomia, em contraposição às abordagens informativas e/ou prescritivas sobre drogas - e as funções do material, quais sejam: estimular a troca de saberes, o diálogo, o compartilhamento de experiências e a reflexão sobre os temas abordados, contribuindo para um processo de aprendizagem prazeroso e interativo.

0 desenho do estudo resulta de uma dissertação de mestrado (ADADE, 2012) e fundamenta-se no pressuposto de que as práticas educativas sobre drogas precisam ser embasadas pelo conhecimento da realidade dos sujeitos e orientadas por abordagens pedagógicas participativas e dialógicas. Conhecer a realidade é uma tarefa ampla e complexa, pois significa investigar as condições materiais de existência (perfil socioeconômico) e os aspectos culturais e simbólicos que permeiam e constituem os sujeitos da ação educativa e suas experiências e visões acerca do tema tratado (CANOLETTI; SOARES, 2005; CARLINI-COTRIM, 1992; FEFFERMANN; FIGUEIREDO, 2006; SOARES, 1997, 2007; SOARES; JACOBI, 2000).

As abordagens educativas dialógicas e participativas compreendem o processo de aprendizagem como um diálogo de saberes entre educador e educando, e a realidade como um todo complexo e multideterminado em que os acontecimentos não são naturalizados. Esse enfoque busca facilitar o reconhecimento da 
intencionalidade das ações sociais e de diferenças socioculturais a partir da problematização do tema abordado de modo a propiciar um olhar crítico acerca da realidade (ACSERALD, 2005; MONTEIRO; REBELLO, 2005).

\section{Percurso metodológico}

As representações sociais são aqui concebidas como imagens, concepções e ideias sobre a realidade compartilhada por determinado grupo, demonstrando a visão consensual nele presente. As representações e práticas sociais se manifestam por meio de sentimentos, discursos, pensamentos e ações expressas, especialmente, pela linguagem (JODELET, 2001). Para investigar as representações e práticas sociais dos estudantes sobre drogas e temas afıns, foram utilizadas estratégias metodológicas de caráter qualitativo, como entrevistas individuais $\mathrm{e}$ observações de campo. A abordagem qualitativa se caracteriza pela compreensão da realidade como uma construção social e dialética, uma vez que todo e qualquer fato concreto está intrinsecamente relacionado a uma forma simbólica, constituída no e constituinte do campo social. Para conhecer e compreender o caráter subjetivo e interpretativo de aspectos da vida social, faz-se necessário contemplar as interações sociais (que são atravessadas por esses sentidos e significados), integrando-as com a análise dos contextos social, cultural e material que servem de contorno para os sujeitos da pesquisa (BECKER, 1994; MINAYO, 2006, 2010).

\section{Caracterização do universo do estudo}

Os dados sobre o consumo de drogas entre estudantes do Estado do Rio de Janeiro são encontrados no trabalho de Galduróz et al. (2004). No entanto, não há um detalhamento dos achados no que se refere a regiões e bairros específicos. Tendo em vista essa lacuna e o caráter qualitativo deste estudo, a seleção das unidades de ensino foi orientada por contatos junto às Secretarias Estadual e Municipal de Educação do Rio de Janeiro, pela disponibilidade da direção da escola e dos alunos em participar do projeto e pela localização geográfica da escola. A pesquisa foi realizada na unidade de ensino indicada pela Secretaria Estadual de Educação, que justificou a indicação esclarecendo que tal instituição enfrentava muitos problemas com drogas em razão de sua localização. No caso da escola indicada pela Secretaria Municipal, a despeito do atendimento de todos os requisitos solicitados, a direção da unidade não autorizou a realização da pesquisa. A solução se deu por meio de um contato pessoal com a diretora de outra escola municipal.

Quanto à seleção da unidade privada, foram contatadas escolas geograficamente próximas das unidades públicas de ensino. Das cinco escolas, apenas duas responderam, não autorizando o desenvolvimento do estudo devido às implicações da abordagem do tema drogas para os familiares dos alunos e à falta de compatibilidade da agenda escolar para realização das entrevistas. Novamente a solução se deu a partir de contatos pessoais. A literatura aponta para a dificuldade de inserção dessa temática no contexto escolar (CARLINI, 2005). É ilustrativo que o CEBRID (Centro Brasileiro de Informações sobre Drogas Psicotrópicas), responsável pela realização de levantamentos sobre o consumo de drogas entre estudantes de todas as capitais brasileiras desde o ano de 1997, somente em sua sexta edição apresenta dados do universo particular.

Participaram do estudo alunos de três escolas: uma estadual, localizada na Tijuca (bairro da zona norte do município do Rio de Janeiro); uma municipal, em Duque de Caxias (município contíguo ao município do Rio de Janeiro); e uma particular, em Teresópolis (Região Serrana do Estado). As três regiões apresentam perfil socioeconômico diversificado, mas têm em comum a presença de tráfico de drogas no entorno dos estabelecimentos de ensino. 0 universo da pesquisa compreendeu 40 estudantes, de 11 a 19 anos, sendo 20 do sexo feminino (metade da escola pública e metade da 
escola privada) e 20 do sexo masculino (metade da escola pública e metade da escola privada). No total, foram: da rede privada, 10 estudantes do ensino médio e 10 do ensino fundamental; da rede pública, 20 estudantes distribuídos do mesmo modo.

A seleção dos sujeitos se deu a partir da divulgação da pesquisa nas salas de aula das três escolas. Apresentou-se o Jogo da Onda e expôsse o objetivo de atualizá-lo. Em cada sala de aula visitada foi deixada uma folha a ser preenchida com nome e contato dos alunos que gostariam de participar da entrevista. Esclareceu-se que a seleção seria feita a partir do sorteio dos interessados, que a participação era voluntária, que os dados eram sigilosos e que os pais e/ou responsáveis precisariam autorizar.

\section{Estratégias metodológicas}

A defınição das estratégias foi norteada pelo percurso metodológico que originou o Jogo da Onda, caracterizado pela investigação do conhecimento, das representações e das práticas sobre drogas por parte de estudantes, bem como pela revisão da bibliografia e de propostas educativas relativas ao tema (MONTEIRO; REBELLO, 2005).

$\mathrm{Na}$ primeira etapa foram realizadas 40 entrevistas semiestruturadas e observações de campo referentes às interações ocorridas nos contextos investigados, considerando-se os aspectos sociais, culturais e materiais. 0 roteiro da entrevista incluiu: perfil socioeconômico; trajetória escolar; visões, conceitos e experiência sobre drogas; relação entre drogas e mídia; motivações e prazeres; drogas e legislação; pressão social; dificuldades na vida cotidiana; visão acerca do usuário de drogas; relações entre sexualidade, Aids e drogas; relações interpessoais; e tipo de educação sobre drogas recebida. Todas as entrevistas aconteceram nas dependências das escolas, em um único contato individual durante o horário de aula. A assinatura do termo de consentimento concedeu a autorização dos responsáveis dos estudantes para a participação no estudo e a gravação das entrevistas.

Os relatos foram transcritos e lidos de forma exaustiva, visando à organização e à codificação do conteúdo segundo os eixos temáticos do roteiro da entrevista e das questões do estudo, bem como à identificação do significado das narrativas (BECKER, 1994). 0 processo de interpretação das informações buscou articular as categorias identificadas nas entrevistas com as informações das observações de campo, os objetivos do estudo e a revisão da literatura do campo das ciências sociais e da educação sobre drogas (ACSERALD, 2005; BUCHER, 1992, 2007; BUCHER; OLIVEIRA, 1994; MACRAE, 1997, 1999; SOARES 1997, 2007; VELHO, 1999; ZALUAR, 1999.

A segunda etapa, referente à revisão e à atualização do conteúdo do jogo, orientouse pela metodologia de criação do material (MONTEIRO; REBELLO, 2005). Para tanto, foram realizadas: 1) análise das publicações sobre o processo de avaliação e repercussão do Jogo da Onda em contextos de ensino (REBELLO; MONTEIRO; VARGAS, 2001; MONTEIRO; VARGAS; REBELLO, 2003) e dos relatórios sobre as etapas de desenvolvimento e avaliação das cartas do material, disponíveis no LEAS/ Fiocruz; 2) revisão bibliográfica sobre o cenário contemporâneo relacionado ao consumo de drogas, centrada em informações, pesquisas científicas sobre o tema, políticas públicas na área da saúde e da educação e legislação;2 3) revisão do conteúdo das 145 cartas da primeira edição do Jogo da Onda a partir dos achados da literatura e das entrevistas com os jovens. Tal análise visou identificar a atualidade e a defasagem do conteúdo das cartas do jogo educativo.

\footnotetext{
2- 0 processo de levantamento bibliográfico se deu no portal de periódicos Scielo e nas bases de dados Lilacs e Scopus, a partir dos seguintes descritores: uso indevido de drogas e adolescência (ou juventude), educação ou prevenção e RD e outras possíveis combinações. Foram incluídos na revisão artigos, teses e livros que abordassem o tema, bem como contatos com profissionais da área em busca de sugestões e indicações bibliográficas.
} 


\section{Resultados e discussão}

Os estudantes das escolas públicas referiram, com maior frequência, que residiam com uma família ampliada, constituída pelo agrupamento de diferentes parentes (avô, tia e prima; tios, irmãos e mãe). 0 número de pessoas residentes nas casas foi maior, variando de 3 a 11. Nesses contextos, a responsabilidade pela educação dos jovens é mais descentralizada, ficando a cargo de todos os adultos; alguns estudantes ajudavam financeiramente e nas atividades domésticas. $\mathrm{Na}$ unidade privada foram mais comuns as famílias nucleares, compostas somente por pais e filhos(as).

Dentre os 40 entrevistados, a maioria possui computador em casa $(92,5 \%)$, tem acesso à internet (82\%) e participa de redes de relacionamentos virtuais (97,5\%). Em relação ao perfil socioeconômico dos entrevistados oriundos de unidades de ensino públicas e privada, foram observadas diferenças relativas à constituição familiar, à inserção profissional dos pais, à possibilidade de acesso a práticas de consumo e a oportunidades de lazer e aprendizagem. Todavia, foram identificadas aproximações relacionadas aos parâmetros e às referências identitárias compartilhadas por uma geração, como o acesso à internet e a valorização de bens de consumo.

A maior parte dos alunos (85\%) possui representações negativas acerca do consumo de drogas. Segundo os jovens, o uso de drogas, principalmente de drogas ilícitas, é sempre uma experiência abusiva e maléfica, sendo o usuário o único responsável por essa interação. Tal visão individualizada e descontextualizada do fenômeno converge com a racionalidade técnico-científica, pautada no discurso de guerra às drogas historicamente difundido em diversos fóruns, inclusive nas escolas (BUCHER; OLIVEIRA, 1994; CARLINI-COTRIM, 1992).

A concepção de prevenção primária do uso de drogas tem como a priori apenas os aspectos danosos da droga (ilícita) e a orientação de que o consumo de qualquer droga deve ser evitado. Esses pressupostos se distanciam da realidade experimentada pelos jovens, dado que as drogas estão presentes em diversos contextos e figuram como instrumento de socialização. 0 não reconhecimento de aspectos contextuais, como a pressão social e o acesso facilitado às drogas, torna os jovens mais vulneráveis ao uso indevido, uma vez que não legitima as possíveis influências presentes em seus espaços de circulação. Ademais, contribui para a manutenção do estereótipo do usuário de drogas como o fracassado e o desviante, facilitando a construção de posturas discriminatórias e dificultando a percepção da condição de usuário de drogas. Conceber todas as dimensões existentes no ato de consumir drogas implica constatar que as alterações ocasionadas transcendem o espectro de puramente fisiológico e envolvem aspectos subjetivos e construções sociais acerca de determinada substância. Os efeitos de uma droga dependem da complexa interação do sujeito (sua fisiologia integrada à sua dimensão subjetiva e simbólica) com a substância específica (suas propriedades químicas e seus significados sociais) em dado contexto, levando-se em consideração toda sorte de fatores aí presentes (BECKER, 2008).

Pouco mais da metade dos entrevistados $(52,5 \%)$ conseguiu diferenciar, de forma breve e superficial, as drogas lícitas das drogas ilícitas. Para muitos, essa diferenciação é orientada pela ideia de que as drogas lícitas causam menos prejuizos e por isso são permitidas. A dificuldade em justificar as origens de tal classificação não se restringe ao universo desta pesquisa, mas resulta do discurso proibicionista que oculta os diversos fatores que rivalizam na complexa interação sujeito-droga e justifica a proibição de determinadas substâncias a partir de critérios farmacológicos. Ou seja, focaliza somente as substâncias e não a rede de elementos que estão presentes nessa interação e que influenciam as motivações sociais, politicas e, especialmente, econômicas da classificação das drogas (ESCOHATADO, 2004; MACRAE, 1997). Noto et al. (2003) afirmam que os psicoativos, apesar de similares em várias características 
farmacológicas, são classificados, legalizados e divulgados de modo diferenciado, o que pode gerar, por sua vez, ideias e práticas incoerentes que precisam ser alvo das ações educativas.

As motivações do uso de drogas ilícitas são associadas às ideias de doença, descontrole, infelicidade, criminalidade, fraqueza e loucura, coerentes com o discurso reducionista que encerra o sujeito em sua condição de usuário, adoecido e/ou criminoso. Segundo Rodrigues (s.d.), a diferenciação entre o usuário e o traficante, já presente na legislação da década de 1970 e reeditada na Lei $n^{\circ}$ 11.343/06, reforça uma possível troca de estereótipos atrelados à pessoa que consome drogas. 0 lugar de doente do usuário de drogas ilícitas se materializa quando este é penalizado a partir do encaminhamento ao tratamento específico na área. Significados e representações existem e são construídos socialmente ao longo do tempo, estando, a cada momento, atrelados a valores, crenças, interesses e motivações de diversas ordens. A percepção dos estudantes acerca dos usuários de drogas, além de se configurar como um obstáculo para o reconhecimento de um uso abusivo, sinaliza a importância de o tema ser incluído nas práticas educativas visando também amenizar a difusão de estereótipos e, consequentemente, de posturas discriminatórias ante os sujeitos que consomem drogas ilícitas.

Ainda no que se refere aos fatores desencadeadores da experiência inicial com as drogas, a maioria dos entrevistados privilegiou elementos relacionados ao entorno social. Os jovens reconhecem somente a presença de elementos da dimensão microssocial, como as mediações sociais (entre amigos, familiares e outros) e características pessoais, como baixa autoestima, personalidade fraca, Maria vai com as outras etc. A valorização de aspectos relacionados ao contexto mais próximo, além de responsabilizar - e muitas vezes culpabilizar - o individuo pela escolha de consumir drogas, desconsidera toda a gama de elementos de ordem macrossocial presentes. Dentre tais elementos, podemos citar o incentivo ao consumo de diversos bens (como as substâncias psicoativas), as diferentes condições socioeconômicas dos grupos populacionais e os elementos que influenciam diretamente na construção de hábitos e atitudes (como no caso de opções de lazer, de diversão, nas formas de lidar com os problemas etc.) (ALMEIDA; EUGÊNIO, 2007; SOARES, 2007).

Conclui-se que os entrevistados têm informação sobre várias drogas, mas não consideram os diferentes tipos de consumo. No caso das substâncias ilícitas, a experimentação é associada à dependência, sendo escassos os relatos sobre o uso recreativo ou ocasional de drogas. A forte introjeção de que a atitude correta é não ter o primeiro envolvimento com qualquer tipo de droga contrasta com a realidade vivenciada - que inclui o consumo de álcool - e com os efeitos danosos do álcool entre jovens (BASTOS et al., 2008; GALDURÓZ et al., 2010). Tal fato ganha relevância na medida em que grande parte dos entrevistados não identifica o álcool como droga; mesmo aqueles que o definiram como droga e que afırmaram consumilo, ao longo da entrevista responderam que não usavam drogas. 0 não conhecimento dos tipos e das possíveis implicações das diferentes formas de consumo dificulta o reconhecimento dos usos devido e indevido (SILVEIRA FILHO, 2007). Em relação às experiências pessoais com drogas ilícitas, apenas uma estudante da escola privada relatou ter usado maconha e ecstasy, pontualmente. Outra disse ainda não ter experimentado o ecstasy, mas compartilhou a curiosidade de experimentar.

As observações de campo e os depoimentos indicaram maior espaço para o diálogo na escola privada. Apesar de a maioria desses alunos não participar de ações educativas sobre drogas, eles mencionaram atividades sobre o tema no contexto escolar, principalmente nas aulas do professor de biologia, com quem demonstraram nutrir uma relação de proximidade e admiração. Tais aspectos possivelmente influenciaram a forma como os conteúdos foram tratados, no sentido de haver um espaço para a exposição 
de perguntas, dúvidas e trocas. Por outro lado, os estudantes das unidades públicas relataram atividades educativas sobre drogas em contextos não escolares, predominantemente no formato de palestras, e consideraram a experiência negativa, sobretudo pela ausência de interatividade. De acordo com eles, as palestras e exposições em sala de aula privilegiam um caráter informativo e relatos de pessoas que tiveram experiências com drogas. A atenção a esse último formato de atividade é necessária para profissionais que trabalham na área de educação sobre drogas, uma vez que tais relatos podem vir a reproduzir uma visão alarmista e reduzida acerca do fenômeno. Ao se contemplar somente a dimensão (e a responsabilização) individual, os aspectos contextuais são omitidos pelo realce dado aos prejuízos da interação. 0 foco nos danos tem a intenção de garantir que as pessoas rejeitem qualquer tipo de consumo (de drogas ilícitas) a partir da mobilização do medo. Ou seja, usa-se o recurso do amedrontamento, ofuscando a consciência crítica para questionar o relato apresentado e seus elementos constituintes (FERREIRA et al., 2010; MONTEIRO; REBELLO, 2005).

Embora a polícia tenha como função assegurar a proteção dos sujeitos e a manutenção da ordem pública, a maioria dos estudantes desacredita nas atividades policiais, caracterizadas como ações predominantemente repressivas e punitivas. No caso do consumo de substâncias ilícitas, os jovens afirmam que a questão deve ser tratada pela saúde pública e não pela justiça. Tal visão nos remete para a atual discussão sobre os limites da autorização para que os policiais façam a distinção entre usuário e traficante, o que está previsto na lei de drogas (Lei $n^{\circ} 11.343 / 06$ ) e vem ocasionando uma explosão carcerária de usuários presos como traficantes no país (ABRAMOVAY, 2012).

Sobre a relação entre drogas e Aids, mais da metade dos entrevistados afirmou desconhecer as possíveis implicações dessa articulação. Apenas um aluno da rede privada associou o compartilhamento de drogas injetáveis à infecção do vírus HIV, conhecimento, segundo ele, adquirido em aula de biologia. Outros afirmaram que o uso de drogas pode alterar a consciência e facilitar a prática do sexo sem preservativo ou uma postura promíscua. A relação entre sexo, Aids e drogas remeteu os estudantes à noção de falta de controle, expressa por comportamentos arriscados na busca pelo prazer, mas distanciado da realidade deles, a despeito de haver consumo, principalmente de álcool, no grupo (JEOLÁS; PAULILO, 1999).

Os entrevistados afirmaram conversar com os pais e/ou familiares sobre relacionamentos amorosos e sexo (70\%) e sobre drogas (62,5\%). A maioria gosta e tem interesse em dialogar sobre drogas, mas as conversas são predominantemente pautadas por orientações para o não uso, como ilustra a fala de um aluno: "quando eles já dizem o que é pra fazer, a gente não tem muita escolha, né?". Outro ponto destacado refere-se ao fato de, muitas vezes, os pais e/ou responsáveis desconhecerem o que deve ser dito ("não sabem o que dizer"), por constrangimento ("eu acho que eles sentem vergonha") ou "falta de conhecimento". Ou seja, os entrevistados ressaltaram a importância do diálogo em casa, destacando o papel da família na constituição do sujeito, mas apontaram a carência de informações e a falta de preparo dos pais para abordar o assunto. Esses dados reiteram a importância de se fornecerem subsídios educativos capazes de fomentar o conhecimento e o diálogo sobre drogas entre jovens, pais e educadores, tendo por base as demandas, as curiosidades e os interesses dos jovens, tal como proposto pelo Jogo da Onda.

Cabe destacar que mais da metade dos entrevistados afirmou ter algum familiar que usa drogas lícitas (álcool e tabaco) e um terço mencionou o uso de drogas ilícitas (maconha, ecstasy, cocaina) entre familiares. Nenhum deles informou o uso de psicofármacos ou de drogas ilícitas pelos pais na ocasião. No entanto, dois estudantes da rede pública relataram que seus pais foram usuários de drogas ilícitas e se envolveram com o tráfico de drogas. Existem vários fatores interdependentes 
relativos às motivações para o consumo (in) devido de drogas; ter um familiar usuário não é determinante para o uso ou abuso de drogas, mas as relações familiares pautadas por um vínculo afetivo e por uma interação saudável colaboram para o desenvolvimento de potencialidades do sujeito e para a redução do uso indevido de drogas (SCHENKER; MINAYO, 2005). Dessa forma, as propostas educativas a esse respeito devem integrar os diversos atores e as instituições que participam da formação dos jovens, como a escola e a família (MOREIRA; SILVEIRA; ANDREOLI, 2006).

Os relatos dos alunos confirmam os achados da literatura sobre educação e drogas relativos aos seguintes aspectos: falta de propostas educativas continuadas, predomínio da concepção de responsabilização individual, ênfase na repressão do consumo de determinadas drogas e manutenção de visões empobrecidas que desconsideram fatores comumente experimentados pelos sujeitos, como a pressão social, a curiosidade e a sensação de bem-estar, entre outros (ACSERALD, 2005; SOARES et al., 2011).

0 interesse pelo tema e a menção positiva da experiência da entrevista sinalizam que os estudantes valorizam práticas baseadas em trocas relacionais viabilizadas pelo diálogo, pelo respeito e pela confiança, elementos facilitadores da livre expressão de dúvidas e experiências. Faz-se necessário investir no conteúdo e, especialmente, no formato dos dispositivos de educação sobre drogas capazes de criar práticas que priorizem a construção de espaços para que os jovens falem de sentimentos, vivências e dúvidas, estabelecendo um diálogo com seus pares, pais e educadores. Nessa direção, as ações educativas devem contemplar os pais e/ou responsáveis pelos jovens, visando orientálos sobre o manejo do tema e trabalhando suas crenças a esse respeito (SCHENKER; MINAYO, 2005; SOARES, 1997).

0 interesse dos jovens por atividades dinâmicas e criativas que privilegiem a troca relacional e estimulem a criatividade reitera a importância da revisão e da atualização do conteúdo do Jogo da Onda para uma futura reedição, tal como descrito a seguir.

Jogo da Onda: mesmo formato, novos conteúdos

Os achados das entrevistas e da revisão da literatura evidenciaram que o conteúdo da maioria das cartas do Jogo da Onda continua atual. Conforme assinalado, muitos jovens não consideraram o álcool e o tabaco como drogas e demonstraram dificuldade em diferenciar as substâncias lícitas e ilícitas. De igual modo, o uso indevido de medicamentos não é associado ao consumo de drogas, embora a OMS (Organização Mundial da Saúde) aponte para as consequências da superprescrição, da automedicação e do abuso de ansiolíticos em diferentes países, incluindo o Brasil (ORLANDI; NOTO, 2005).

Em suma, embora os estudantes tenham informações sobre os diferentes tipos de droga, prevalecem respostas equivocadas sobre seus efeitos. Desse modo, é importante manter e ampliar as cartas centradas nos prejuízos do consumo de drogas lícitas, na diferenciação entre as substâncias (a partir do status de legalidade e ilegalidade) e na divulgação da definição das substâncias no que se refere aos efeitos, além de inserir uma breve contextualização da droga.

Outro ponto bastante presente nos relatos diz respeito à influência dos pares como uma das motivações centrais para o consumo de drogas, aspecto que tem sido assinalado pela literatura (ACSERALD, 2005; ALMEIDA; EUGÊNIO, 2007). No entanto, a maioria dos estudantes não falou de si diretamente. A pesquisa que deu origem à primeira edição do Jogo da Onda igualmente identificou a tendência dos jovens de não abordar o tema a partir de suas próprias experiências. Os estudantes reconheciam a existência da pressão social, mas não se sentiam atravessados por ela (REBELO; MONTEIRO; VARGAS, 2001).

Demais estudos assinalam que o discurso dos jovens tende a focalizar a experiência de 
terceiros; os relatos de experiências pessoais sobre o consumo de drogas (em geral, ilícitas) são mais escassos, possivelmente em razão de ser algo ilegal, sujeito a sanções. Poucos mencionaram o prazer e a busca por sensações de bem-estar. 0 conteúdo das cartas originais que abordam esses temas está atualizado. Coerente com a fundamentação teórica do material educativo, que combina a perspectiva da educação para autonomia com a RD, o desenvolvimento do conteúdo do jogo não só abordou e incorporou temas que surgiram de demandas dos jovens, como adotou uma dinâmica que facilita a participação dos jogadores. Ainda nessa direção, as autoras optaram por privilegiar, no conteúdo das cartas, situações envolvendo terceiros que discutissem diferentes aspectos do consumo de drogas e temas afins (MONTEIRO; VARGAS; REBELLO, 2003; SCHENKER; MINAYO, 2005; SOARES, 2007).

Os relatos apontam para o desconhecimento dos alunos acerca de algumas transformações no cenário do consumo e comércio de drogas, como as mudanças legislativas, que têm sido divulgadas pela imprensa. Tais dados reforçam a contribuição do Jogo da Onda na divulgação e na discussão de informações atuais sobre o tema. Nesse sentido, sugere-se a inclusão de novas cartas relativas às legislações mais recentes, bem como às implicações de situações de discriminação dos usuários perante as associações entre uso de drogas, criminalidade, descontrole e adoecimento. Propõe-se, ainda, a incorporação de cartas sobre as repercussões das novas formas de sociabilidade contemporânea, como as redes digitais, e das diversas formas de consumo (materiais e simbólicas) e suas implicações para o fenômeno das drogas - nesse contexto, vistas como mercadorias de consumo que mobilizam interesses, movimentações econômicas etc. Objetiva-se também inserir cartas sobre estratégias de RD, como informações sobre os possíveis riscos de associação de uma substância com outras drogas, devido às interações tóxicas.

Como desdobramento do estudo, os novos conteúdos propostos passarão pelo mesmo processo de testagem que caracterizou a construção e a avaliação da primeira edição do Jogo da Onda, configurada pela realização de grupos focais com estudantes e observações do uso. Após esse processo, objetiva-se encaminhar uma segunda e nova edição do jogo.

\section{Considerações finais}

As reflexões apresentadas indicam que o consumo de drogas se conecta a aspectos históricos, socioculturais, econômicos, políticos e individuais. 0 manejo do tema no contexto educacional depende, entre vários fatores, de processos formativos e da disponibilidade do educador. Isso significa dizer que o desenvolvimento de ações educativas deve privilegiar a capacitação continuada de educadores e a oferta de recursos/estratégias educativas, contemplando, tal como propõe a abordagem de RD, o conhecimento, as crenças e os sentimentos que o tema mobiliza, bem como a contextualização do fenômeno a partir de uma perspectiva educativa dialógica e participativa.

Conforme assinalado por Soares (2007), é preciso reconhecer as dificuldades de se assumir uma perspectiva sobre drogas orientada pela $\mathrm{RD}$, que, apesar de solidamente fundamentada, ainda é emergente e alvo de críticas combativas. A busca pela construção de argumentos se faz necessária para a sustentação de um posicionamento claro e seguro diante de questionamentos e censuras. Tratar o tema amplamente, valorizando todas as suas dimensões, implica enfrentar as críticas de diferentes atores sociais e fornecer esclarecimentos e informações coerentes e sérias, as quais nem sempre são divulgadas, embora atualmente estejam mais acessíveis (CANOLETTI; SOARES, 2005).

Este trabalho teve o propósito de contribuir para o desenvolvimento e o aprimoramento de práticas educativas sobre drogas e fomentar reflexões sobre as relações entre a abordagem da redução de danos e a perspectiva da educação para a autonomia. Em 
um sentido mais global, o trabalho integra um movimento - já instaurado e que gradualmente vem se solidificando - de difusão de discursos contra-hegemônicos, procurando divulgar novos conhecimentos contextualizados sobre o tema do consumo de drogas e seus desdobramentos. Assim, ao materializar tal perspectiva em um jogo educativo, o desenvolvimento desta pesquisa demonstra o comprometimento em afınar a teoria à prática.

\section{Quadro 1 - Jogo da Onda}

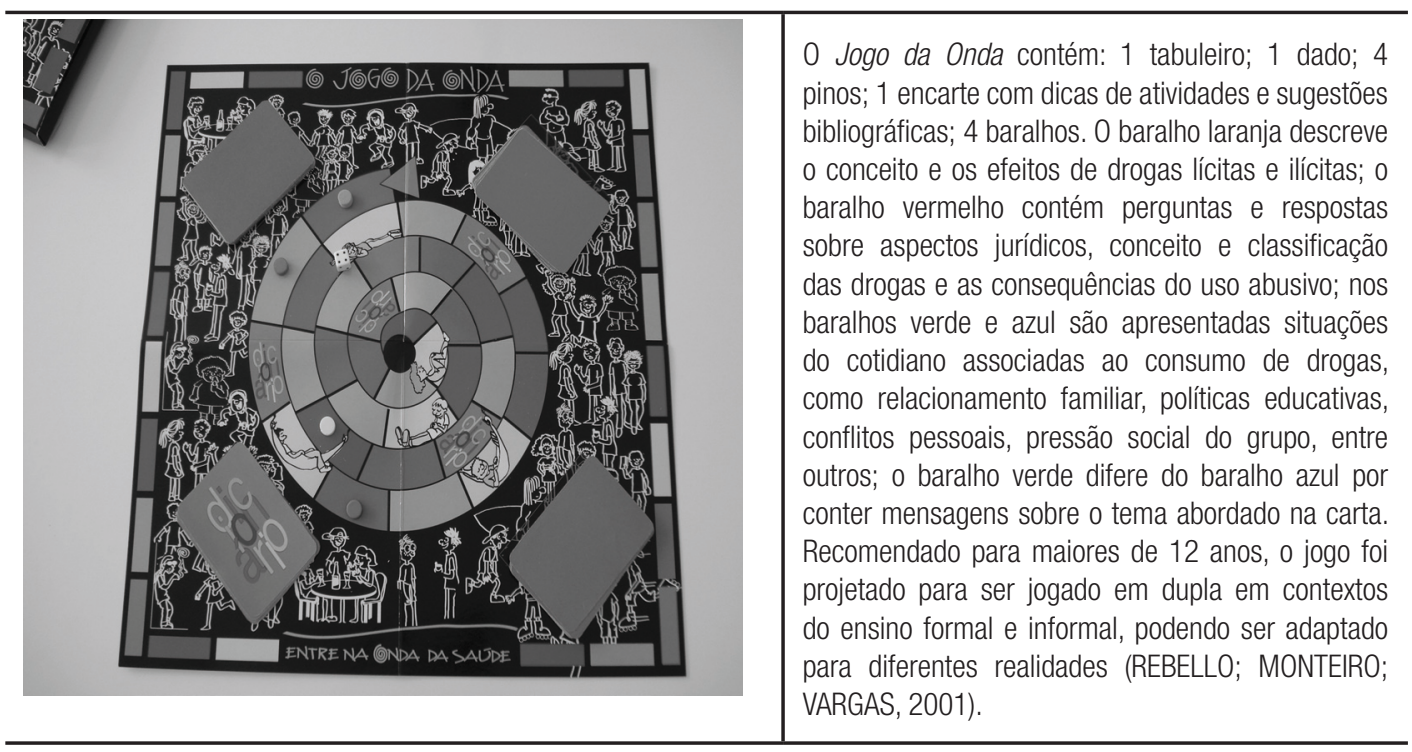




\section{Referências}

ABRAMOVAY, Pedro. Usuário pobre está sendo tratado como traficante: depoimento. [23 jul. 2012]. Entrevistador: Felipe Prestes. Porto Alegre: Sul21, 2012. Disponível em: <http://www.sul21.com.br/jornal/2012/07/pedro-abramovay-o-usuariopobre-esta-sendo-tratado-como-traficante/>. Acesso em: 3 out. 2012.

ACSERALD, Gilberta. A educação para a autonomia: a construção de um discurso democrático sobre o uso de drogas. In:

(Org.). Avessos do prazer: drogas, Aids e direitos humanos. 2. ed. Rio de Janeiro: Fiocruz, 2005. p. 161-188.

ADADE, Mariana. A visão de estudantes sobre drogas: subsídios para ações educativas orientadas pela redução de danos. Dissertação (Mestrado) - Instituto Oswaldo Cruz, Rio de Janeiro, 2012.

ALMEIDA, Maria Isabel; EUGENIO, Fernanda. Paisagens existenciais e alquimias pragmáticas: uma reflexão comparativa do recurso às "drogas" no contexto da contracultura e nas cenas eletrônicas contemporâneas. In: ALMEIDA, Maria Isabel; NAVES, Santuza Cambraia (Orgs.). Por que não? Rupturas e continuidades da contracultura. Rio de Janeiro: 7 Letras, 2007. p. 155-200.

ARAÚJO, Ulisses. Temas transversais em educação: bases para uma formação integral - apresentação à edição brasileira. In: BUSQUETS, Maria Dolors et al. Temas transversais em educação: bases para a formação integral. São Paulo: Ática, 2001. p. 9-17.

BASTOS, Francisco et al. Consumo de álcool e drogas: principais achados de pesquisa de âmbito nacional, Brasil 2005. Revista de Saúde Pública, São Paulo, v. 42, supl. 1, p. 109-117, 2008.

BECKER, Howard. Métodos de pesquisa em ciências sociais. São Paulo: Hucitec, 1994.

Outsiders: estudos de sociologia do desvio. Rio de Janeiro: Jorge Zahar, 2008.

BIZZOTTO, Alexandre; RODRIGUES, Andreia. Nova lei sobre drogas: comentários à lei n. 11.343, de 23 de agosto de 2006. Rio de Janeiro: Lúmen Júris, 2007.

BOFF, Eva et al. Drogas: uma proposta de organização curricular que articula formação docente. In: ENCONTRO NACIONAL DE PESQUISADORES EM EDUCAÇÃO EM CIÊNCIAS, 7., 2009, Florianópolis. Anais... Florianópolis, 2009.

BUCHER, Richard. Drogas e drogadição no Brasil. Porto Alegre: Artes Médicas, 1992.

. A ética da prevenção. Psicologia: Teoria e Pesquisa, Brasília, v. 23, n. especial, p. 117-123, 2007.

BUCHER, Richard; OLIVEIRA, Sandra. 0 discurso do "combate às drogas" e suas ideologias. Revista de Saúde Pública, São Paulo, v. 28, n. 2 , p. $137-45,1994$

CANOLETTI, Bianca; SOARES, Cassia. Programas de prevenção ao consumo de drogas no Brasil: uma análise da produção científica de 1991 a 2001. Interface: Comunicação, Saúde, Educação, Campinas, v. 9, n. 16, p. 115-129, 2005.

CARLINI, Elisaldo. II Levantamento domiciliar sobre o uso de drogas psicotrópicas no Brasil - 2005. São Paulo: CEBRID; Unifesp, 2005.

CARLINI-COTRIM, Beatriz. A escola e as drogas: realidade brasileira e contexto internacional. Tese (Doutorado em Psicologia Social) - Pontifícia Universidade Católica de São Paulo, São Paulo, 1992.

CARLINI-MARLATT, Beatriz. Estratégias preventivas nas escolas. In: SEIBEL, Dario; TOSCANO JÚNIOR, Alfredo (Orgs.). Dependências de drogas. São Paulo: Atheneu, 2001. p. 191-7.

CAVALCANTE, Cláudia et al. Representações de um grupo de docentes sobre drogas: alguns aspectos. Ensaio: Pesquisa em Educação em Ciências, Belo Horizonte, v. 7, n. 2, p. 1-13, 2005.

ESCOHOTADO, Antônio. A história elementar das drogas. Lisboa: Antígona, 2004. 
FEFFERMANN, Marisa; FIGUEIREDO, Regina. Redução de danos como estratégia de prevenção de drogas entre jovens. BIS: Boletim do Instituto de Saúde, São Paulo, v. 40, 2006.

FERREIRA, Tatiana et al. Percepções e atitudes de professores de escolas públicas e privadas perante o tema drogas. Interface: Comunicação, Saúde, Educação, Campinas, v. 14, n. 34, p. 551-62, 2010.

FREIRE, Paulo. Pedagogia da autonomia: saberes necessários a prática educativa. Rio de Janeiro: Paz e Terra, 2008.

GALDURÓZ, José Carlos et al. V Levantamento sobre o uso de drogas entre estudantes do ensino fundamental e médio 27 capitais brasileiras. São Paulo: EBRID; Unifesp, 2004.

GALDURÓZ, José Carlos et al. Fatores associados ao uso pesado de álcool entre estudantes das capitais brasileiras. Revista de Saúde Pública, São Paulo, v. 44, n. 2, p. 267-273, 2010.

JEOLÁS, Leila; PAULILO, Maria Angela. Representações sociais da homossexualidade entre professores do ensino público: continuidades e rupturas. Textos e Contextos, Porto Alegre, v. 7, n. 2, p. 166-185, 2008.

JODELET, Denise. Representações sociais: um domínio em expansão. In: Janeiro: Eduerj, 2001. p. 17-44.

(Org.). As representações sociais. Rio de

MACRAE, Edward. Das drogas: o controle social do uso de substâncias psicoativas. In: PASSETTI, Edson; SILVA, Roberto da (Orgs.). Conversações abolicionistas: uma crítica do sistema penal e da sociedade punitiva. São Paulo: IBCCrim/PEPG Ciências Sociais PUCSP, 1997. p. 108-116.

A importância dos fatores socioculturais na determinação da política oficial sobre o ritual de ayahuasca. In: ZALUAR, Alba (Org.). Drogas e cidadania: repressão ou redução de riscos. Brasiliense: São Paulo, 1999. p. 31-45.

MARTINI, Jussara; FUREGATO, Antonia. Representações sociais de professores sobre o uso de drogas em uma escola de ensino básico. Revista Latino-Americana de Enfermagem, Ribeirão Preto, v. 16, n. especial, p. 601-606, 2008.

MINAYO, Maria Cecília. Contribuições da antropologia para pensar e fazer saúde. In: CAMPOS, Gastão W. de Souza et al. (Orgs.). Tratado de saúde coletiva. São Paulo: Hucitec; Rio de Janeiro: Fiocruz, 2006. p. 189-218.

0 desafio do conhecimento: pesquisa qualitativa em saúde. 12. ed. São Paulo: Hucitec, 2010.

MONTEIRO, Simone; REBELLO, Sandra. Prevenção do HIV/Aids e o uso indevido de drogas: desenvolvimento e avaliação de jogos educativos. In: ACSERALD, Gilberta (Org.). Avessos do prazer: drogas, AIDS e direitos humanos. 2. ed. Rio de Janeiro: Fiocruz, 2005. p. 275-300.

MONTEIRO, Simone; VARGAS, Eliane; REBELLO, Sandra. Educação, prevenção e drogas: resultados e desdobramentos da avaliação de um jogo educativo. Educação e Sociedade, Campinas, v. 24, n. 83, p. 659-678, 2003.

MOREIRA, Fernanda; SILVEIRA, Dartiu; ANDREOLI, Sergio. Situações relacionadas ao uso indevido de drogas nas escolas públicas da cidade de São Paulo. Revista de Saúde Pública, São Paulo, v. 40, n. 5, p. 810-817, 2006.

NOTO, Ana Regina et al. Drogas e saúde na imprensa brasileira: uma análise de artigos publicados em jornais e revistas. Cadernos de Saúde Pública, Rio de Janeiro, v. 19, n. 1, 2003.

ORLANDI, Paula; NOTO, Ana Regina. Uso indevido de benzodiazepínicos: um estudo com informantes-chaves no município de São Paulo. Revista Latino-Americana de Enfermagem, Ribeirão Preto, n. 13, p. 896-902, set./out. 2005.

PAGLIA, Angela; ROOM, Robin. Alcohol and aggression: general population views about causation and responsibility. Journal of Substance Abuse, v. 10, p. 199-216, 1998.

REBELLO, Sandra; MONTEIRO, Simone. 0 jogo da onda: entre na onda da saúde. Rio de Janeiro: Fiocruz: Consultor, 1998 
REBELLO, Sandra; MONTEIRO, Simone; VARGAS, Eliane. A visão de escolares sobre drogas no uso de um jogo educativo. Interface: Comunicação, Saúde, Educação, Campinas, v. 5, n. 8, p. 75-88, 2001.

RODRIGUES, Thiago. Guerra às drogas: ainda e sempre? s.d. Disponível na web: <http://enecos.org/guerra-as-drogas-ainda-esempre/>. Acesso em: 3 out. 2012.

SANTOS, Vilmar; SOARES, Cassia; CAMPOS, Célia. Redução de danos: análise das concepções que orientam as práticas no Brasil. Physis: Revista de Saúde Coletiva. Rio de Janeiro, v. 9, n. 16, p. 115-29, 2010.

. A produção científica internacional sobre redução de danos: uma análise comparativa entre MEDLINE e LILACS. Revista Eletrônica Saúde Mental Álcool e Drogas, v. 8, n. 1, p. 41-7, 2012.

SCHENKER, Miriam; MINAYO, Maria Cecília. Fatores de risco e de proteção para o uso de drogas na adolescência. Ciência \& Saúde Coletiva, Rio de Janeiro, v. 10, n. 3, p. 707-717, 2005.

SOARES, Cassia. Adolescentes, drogas e AIDS: avaliando a prevenção e levantando necessidades. Tese (Doutorado) - Faculdade de Educação, Universidade de São Paulo, São Paulo, 1997.

. 0 consumo contemporâneo de drogas e juventude: a construção do objeto na perspectiva da saúde coletiva. Tese (Livre-docência) - Escola de Enfermagem, Universidade de São Paulo, São Paulo, 2007.

SOARES, Cassia; JACOBI, Pedro. Adolescentes, drogas e Aids: avaliação de um programa de prevenção escolar. Cadernos de Pesquisa, São Paulo, n. 109, p. 212-237, 2000.

SOARES, Cassia et al. Avaliação de ações educativas sobre consumo de drogas e juventude: a práxis no trabalho e na vida. Trabalho, Educação e Saúde, Rio de Janeiro, v. 9, n. 1, p. 43-62, 2011.

SILVEIRA FILHO, Dartiu. Uso recente de álcool, tabaco e outras drogas entre estudantes adolescentes trabalhadores e não trabalhadores. Revista Brasileira de Epidemiologia, São Paulo, v. 10, n. 2, p. 276-87, 2007.

VELHO, Gilberto. A dimensão cultural e política dos mundos das drogas. In: ZALUAR, Alba (Org.). Drogas e cidadania: repressão ou redução de riscos. São Paulo: Brasiliense, 1999. p. 23-29.

WHO (World Health Organization). The world health report: Chapter one. s.d. Disponivel em: <http://www.who.int/whr/2004/ chapter1/en/index5.html>. Acesso em: 14 maio 2013.

ZALUAR, Alba. A criminalização das drogas e o reencantamento do mal. In: redução de riscos. São Paulo: Brasiliense, 1999. p. 97-129. (Org.). Drogas e cidadania: repressão ou

Recebido em: 08.10.2012

Aprovado em: 12.12 .2012

Mariana Adade é psicóloga, gestalt-terapeuta, especialista em Assistência a Usuários de Álcool e outras Drogas pelo Instituto de Psiquiatria da Universidade Federal do Rio de Janeiro (IPUB/UFRJ) e mestra em Ciências pelo Instituto Oswaldo Cruz (IOC/FIOCRUZ).

Simone Monteiro é pesquisadora do Instituto 0swaldo Cruz (FIOCRUZ), onde chefia o Laboratório de Educação em Ambiente e Saúde (LEAS), bolsista de produtividade em pesquisa nível 2 do Conselho Nacional de Desenvolvimento Científico e Tecnológico (CNPq) e doutora em Saúde Pública (ENSP/FIOCRUZ), com pós-doutorado na Columbia University. 